\title{
Building of Green Tourism Supply Chain and Study on Collaborative Optimization from the Perspective of Industrial Convergence
}

\author{
Pu Rong \\ Lijiang Tourism Research Center \\ Lijiang Teacher's College \\ Lijiang, Yunan, 674199 \\ 16110@126.com
}

\begin{abstract}
-the paper analyses the realistic problems of traditional Chinese tourism supply chain from the perspective of industrial convergence. It concludes in general that our supply chain does exist several dramatic problems-loose organizational structures, lacking of flexibility in management, high operation cost, and outstanding negative externality and so on. On this basis, the paper proposes building core enterprises, cooperative mechanism and information platform of green tourism supply chain to promote development of tourism supply chain. At last, the paper puts forward that the building of green tourism supply chain should be collaboratively optimized through the implementation of integrated, virtual and low-carbon tourism supply chain combining the current tourism development tendency and the frontier the ory of supply chain management.
\end{abstract}

Keywords-green tourism supply chain; collaboratively optimized; industrial convergence

\section{INTRODUCTION}

The development of China's tourism industry has entered into a critical stage of strategic upgrading, industrial transformation and structural optimization during the "13th Five-Year Plan” period. The industry has shown a diversity of integrated development, increased multi-level integration, increased integration, endless emergence of new forms of tourism and so on, which greatly reshape the structure and industrial boundaries of the tourism industry. At the same time, low-carbon tourism has become a new consensus, including eco-tourism and circular tourism economy, are all committed to solving negative externality caused by tourism development. However, more researches and efforts are merely focused on transformation of tourism activities, ecological protection of tourist attractions and sustainable development of tourism destinations. The highly complex and decentralized internal structure of the tourism industry has made the implementation of low-carbon tourism strategy a challenge [1]. From the view of the tourism supply chain, these efforts cannot truly achieve the overall goal of low carbonization and sustainable development of the tourism industry, especially under the current circumstance of integrated development, transformation and upgrading of the tourism industry, the low carbonization

Fund projects: Philosophy and social science planning project in Yunnan Province(QN2016007), science and technology planning project in Lijiang (2016LJSFK014), the fourth group of young and middle-aged academic \& technological leaders-assisted project in Lijiang. development of tourism industry is inevitable needing to find a way out in the height of the entire tourism supply chain. In view of this, the paper starts to build a green tourism supply chain system and optimize it collaboratively on the basis of previous researches and new trend of the integration of tourism industry development.

\section{Realistic Problems of the Traditional Tourism SUPPLY CHAIN}

\section{A. Loose organizational structure of supply chain and lacking of cooperative mechanism}

The long-term adversarial competition among China's tourism supply chain companies is fierce. In order to seek more benefits for the company in a relatively stable market, different levels of corporate members in the tourism supply chain (such as travel agencies and hotels, tourist shopping stores, tourist resorts, tourism product suppliers, etc.) use advantages of Party A in the buyer's market to lower purchase prices and impose harsh conditions, and achieve control over suppliers and cooperative enterprises to obtain more profits. Furthermore, other competitors in the supply chain launch more intense price competition, and this low-cost competition eventually caused severe damage among the entire tourism supply chain and no company completely win in the low-price competition [2]. Meanwhile, our tourism industry has had some problems for a long time--small scale, scattered operations, and disorderly management of enterprises. This is mainly due to the fact that the tourism industry is labor-intensive and the threshold is low. The entry and exit of enterprises are more frequent in the lowlevel and fierce competition, and it is difficult for tourism companies to establish a strategic cooperative partnership based on trust and cooperation. The relationship between enterprises is only maintained at the "sales and purchases" level.

\section{B. Lacking of flexibility in the supply chain management and the operation cost is high}

The core competitiveness of the tourism supply chain lies in providing high-quality overall tourism services for tourists. The diversification, individualization, and comprehensive service requirements demonstrated by the tourism market in the 
new era pose challenges to the operation of traditional tourism supply chains. Lack of in-depth cooperation and trust mechanisms, poor information circulation has led to increased coordination costs and time between tourism enterprises. And it is difficult to satisfy customers' flexible needs, for example, travel schedules made by most tour teams are rigid and tourists have no free choice of travel products and services during their travels, and even the time for free activities are minimal. It is difficult for tourists to obtain more experiences and gains beyond sightseeing by complying completely with the rules and regulations in the original contract, and it ultimately reduce the satisfaction of tourists. From the perspective of operation costs, enterprises on the traditional tourism supply chain always take the goal of maximizing their own corporate profits. In the current operation of China's tourism service supply chain, the destination agency usually quotes a relatively low price to attract tourists. However, after the arrival of the tourism team, they tend to increase attractions to charge high fees or increase shopping stores to obtain rebates, and even secretly change the travel contract such as lowering the standard of meals or accommodations. As a result, the interests of tourists are greatly violated.

\section{Outstanding negative externality}

With the growing scale of the tourism industry, the tourism supply chain continues to expand, and the tourism transportation, production and supply of tourism products, consumption, development of scenic areas and tourism infrastructure construction involved in the tourism supply chain bring about great pressure on the environment and resources of the tourism destination. On the one hand, tourists' travel has brought about an increase in carbon emissions. Travel transportation, accommodation, catering, entertainment and other travel activities will bring about a lot of carbon emissions. At present, aviation tourism is the first choice of many longdistance tourists, but the carbon emissions of air travel are 5-7 times than that of railway tourism. Many domestic scholars have introduced the concept of ecological footprint to calculate and evaluate the negative external influence of tourism development on the local ecological environment in a certain area. In some well-known tourist destinations and scenic spots in China, there has been an ecological deficit, indicating the influx of a large number of tourists has caused the insufficient supply of the local ecological production capacity, leading to unsustainable development of tourism destinations [3].On the other hand, in the development of tourism, the tourism industry has become a high energy-consuming and high carbonemission industry because tourism supply chain members lack cooperation and low-carbon awareness in the activities of tourism supplies, production of tourism products, raw material procurement, tourism reception and supporting facilities construction and so on that aim to maintain the operation of tourism activities. Taking the hotel industry as an example, the average electricity consumption per square meter of four-star hotels in China is $150 \mathrm{Kw} / \mathrm{h}$, which is 18 times than that of ordinary residential buildings. The water consumption of each guest room is 5-8 times than that of an ordinary family of three.
III. BuILDING OF CORE ENTERPRISES ON THE GREEN TOURISM SUPPLY CHAIN

\section{A. Building of core enterprises}

1) Supply chain with travel agencies as the core enterprises

The establishment of core position of the travel agency in the tourism supply chain is attributed to the irreplaceable role of the travel agency in controlling the whole process of tourism activities. It is also an important intermediary link connecting hotels, restaurants, transportation, and scenic spots while serving tourists (Fig. 1).It has become a center of tourism information, fund settlement, tourism flow dispatching and communication coordination. These advantages and functions can effectively manage travel orders, implement demand forecasting and rational resources allocation, improve tourism supply chain service levels as well as reduce operating costs. However, travel agencies also face several challenges at present if they want to play the role of core enterprises in the supply chain well. The challenges are as follows: One, the small scale, weak strength and backward business philosophy of travel agencies have constrained their effective impact and intervention on the supply chain; two, lack of innovative ideas and core competitiveness, travel agencies' long-term low-cost competitive strategy is not conducive to leading the entire supply chain to grow; three, China's travel agency has long existed a complex principal-agent relationship, which seriously affects the stability of the tourism supply chain, leading to the loose supply chain structure [4].

\section{2) Supply chain with scenic spots as the core enterprises}

Tourist attractions are the core part of tourists' purchase of tourism products, and the main target choice for travelling. From the reality of the construction of green tourism supply chain, the most important problems restricting and influencing the implementation of green tourism supply chain have been concentrated in the scenic areas in recent years. Due to the drastic increase in the number of tourists, the disorderly development of the scenic areas, the overcapacity reception, and the increased pollution damage lead to sharp decrease in the quality of the important tourism product-tourist attractions and ultimately affect the competitiveness of the entire supply chain. The root cause lies in the unstable supply chain caused by the imbalance between supply and demand in China's current tourism supply chain operations. Driven by profit maximization, the tourism provider, the leader of the travel agency transport a large number of tourists to the scenic spots and reception enterprises in the downstream tourist destinations without limitation during the tourist seasons in general, ignoring the carrying capacity of the tourism destinations and the reception capacity of the scenic spots. The tourist attractions also embrace tourists passively out of interests. While in the off-season, the resort has to rely on travel agencies to attract tourists through more discounts. The situation can easily cause instability in the entire supply chain. In fact, some scenic spots with a certain scale and popularity in China can rely on their own advantages to establish a core enterprise status in the whole supply chain, accelerating the transition from a single-type scenic area to a comprehensive one, and the tourism-type scenic spot to the leisure-type one as well as 
realizing the shift from product management to the improvement and transition of brand and concept management. In view of the fact that many scenic spots in the country are small in scale and dispersed, it is possible to establish an overall branded operation and marketing strategy (Fig. 2).

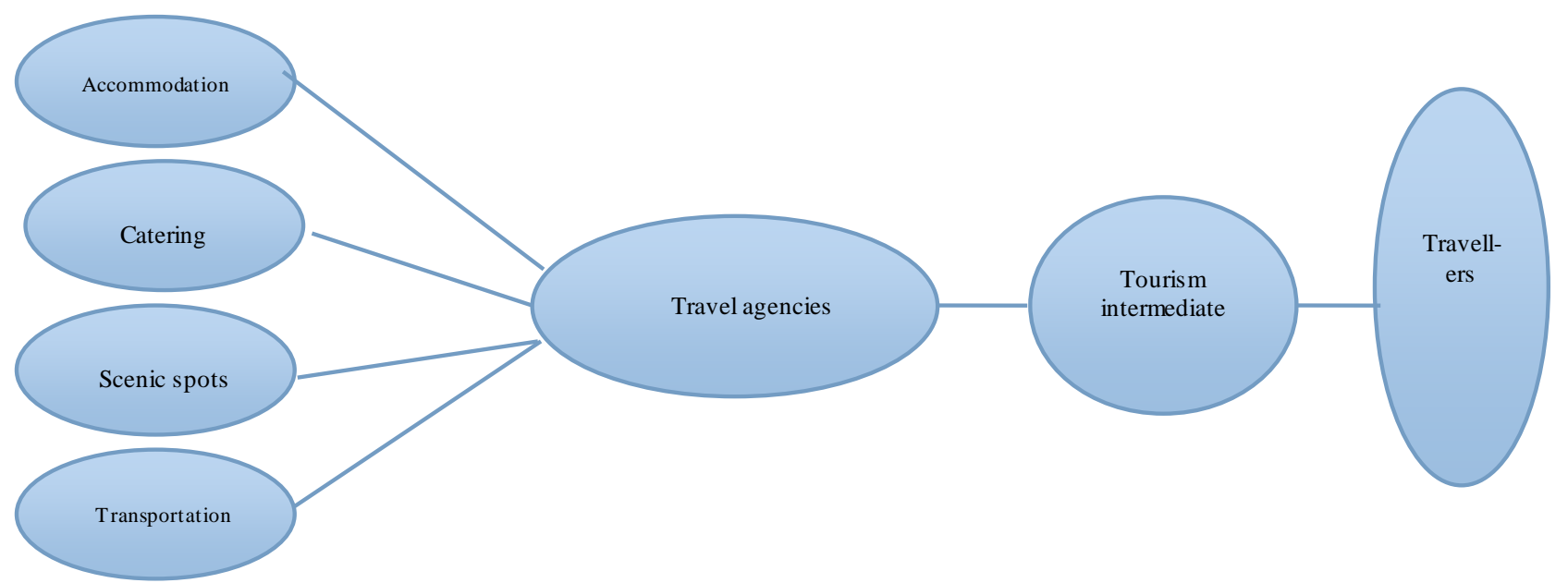

Fig. 1. Simplifying tourism supply chain model with the core of travel agencies

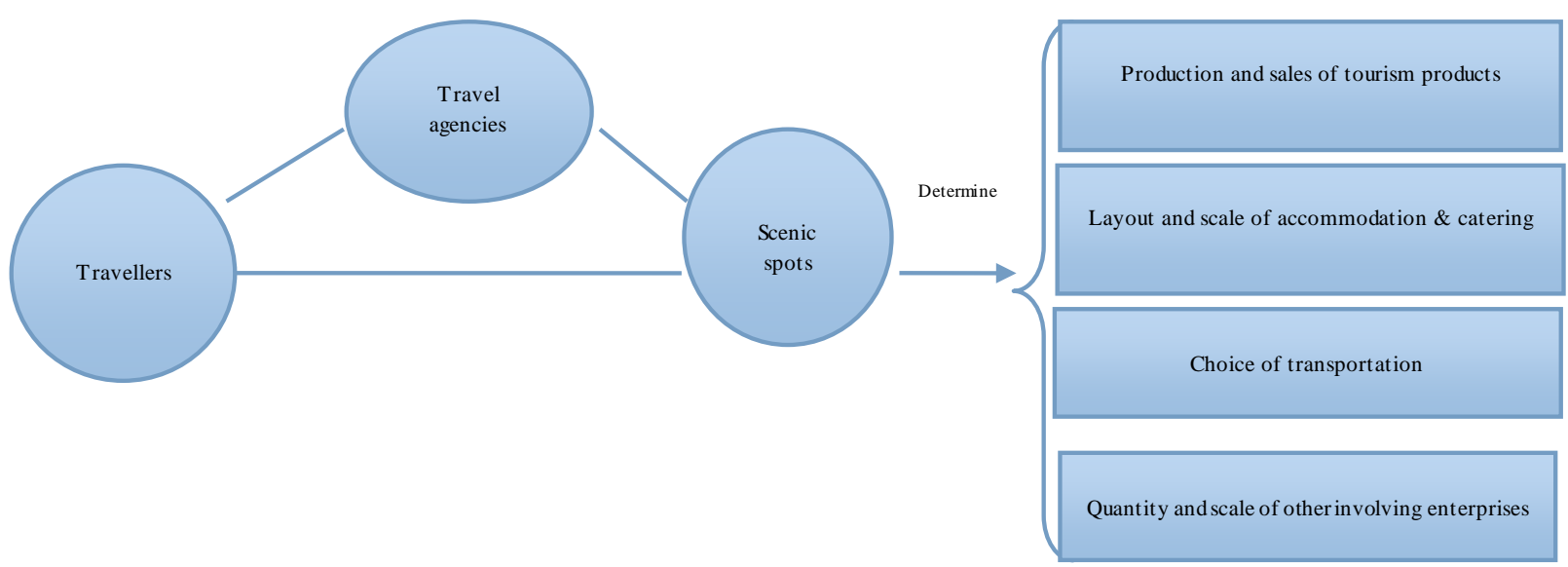

Fig. 2. Simplifying tourism supply chain model with the branded scenic spots as the core enterprises

\section{B. Building of information platform}

Information management is an important part of supply chain management. Supply chain information management has been regarded as the main source of improving operation efficiency of the supply chain and obtaining competitive advantage. Therefore, the key to the successful implementation of supply chain management is to effectively integrate information between supply chain companies, eliminating barriers to information flow and building an information platform to share information among supply chain members. The construction of tourism supply chain information platform needs to realize information sharing in two aspects: First, the platform should involve in information sharing of upstream and downstream companies in the supply chain that the tourism travel activities refer to, including the sharing of travel agencies, ground communications agencies, tourism transport, hotels, restaurants, scenic spots, shopping malls and other related companies; second, is the information sharing between each company and its peer companies. The information sharing between the upstream and downstream of the tourism supply chain can improve the response speed and increase the quality of tourist services. Information sharing between enterprises in the same industry can realize the integration and utilization of resources, such as jointly deploying vehicles, guides, and passenger flow in the tourist season to enhance the overall competitiveness of the supply chain, while also being able to resist uncertainties from the outside world to the tourism industry.

\section{Building of collaborative mechanism}

The core of the establishment of the tourism supply chain member cooperation mechanism is to establish a scientific and 
rational mechanism for profit distribution among enterprises. The implementation of the distribution mechanism requires the participation and involvement of government or tourism agencies to provide policy support and legal protection for the benefit distribution mechanism among supply chain enterprises [5]. In addition, upstream and downstream companies in the tourism supply chain as well as companies and consumers must implement supply chain contracts to achieve overall constraints on supply chain members, establishing a certain supply chain member behavior regulation and rewards \& punishments mechanism, and avoiding the constant goal "maximizing selfprofit" among enterprises. Therefore, in the tourism supply chain, cooperative relationships established between companies through contractual capabilities can effectively constrain the self-centered decision-making behavior of companies on the chain, and the cost constraints and incentives that follow. Ultimately, every company chooses to reduce the marginal cost of the company itself and maximize the overall benefits of itself and the supply chain with self-discipline. In the contract implementation of the upstream and downstream companies in the tourism supply chain, the realization of effective information sharing mechanism and the same authorized price can better realize trust between enterprises. Due to the information asymmetry brought about by the long-term agency system of the tourism industry, the long-term existing problem creates moral hazard for cooperation among companies. The enterprises must rely on information sharing and the same authorized prices to avoid the problem. Based on these protection mechanisms, the overall stability of the supply chain can be ensured regardless of the dynamic changes in the entry and exit of companies in the supply chain.

\section{Collaborative Optimization OF GREen TOURISM SUPPLY CHAIN}

\section{A. Integrated tourism supply chain}

The goal of tourism supply chain integration is to increase the overall competitiveness and agility of the supply chain so that it can quickly respond to market changes. The integration of the tourism industry has expanded the industry scale and created new businesses. However, it has not fundamentally changed the cooperation and interdependence between industries and enterprises. The operation of traditional tourism companies only considers their own abilities and neglects the sharing and re-allocation of enterprise resources in the society. The integrated tourism supply chain is based on the needs of tourists. They are integrated for the use of a product or a service to regard all enterprises and social resources as reconfigurable flexible units. Finally, seamless integration between enterprises is achieved under information integration through business process reorganization to transform traditional tourism service operation modes and the organization and coordination of core enterprises to share and allocate the entire factor resources. It should be said that the application of integrated management ideas in the tourism industry has completely broken down the important enterprise integrated management model in which traditional tourism industry operations are led by travel agencies, tourist transportation, and scenic spots. Under the integrated supply chain management model, emphasis is placed on the integrated management from tourism supply sources to demand sources, regarding all enterprises as a whole. At the same time, the existing partnerships between tourism companies will be further strengthened. The improvement of interest distribution mechanisms and the overall demand on the supply chain will drive the establishment of more intimate and mutual trust strategic partnership. The integration of the enterprises turns from internal to external integration. The external business process reengineering and operation network planning and design will help the overall operation level of the tourism supply chain continue to increase, and ultimately, the enterprises are able to improve tourism service levels and the quick respond to demand through the integration of tourism supply chain.

\section{B. Virtual Tourism Supply Chain}

From the view of tourism industry integration, the extension and mutual penetration of industrial boundaries make the network structure of the tourism supply chain more complex, and the traditional high-cost and low-efficiency operation of the traditional tourism supply chain has been difficult to adapt to the new industry integration in the new era. About tourists, the individualized, comprehensive and complex demand characteristics exhibited by tourists are destined to be difficult for individual companies to provide service requirements for all customers in the current market. Enterprises are focused on their own main business and areas with core competitiveness in the new competitive environment, bringing more business outsourcing and more cooperative members in the supply chain. The complex supply chain network chain will inevitably increase the operating costs. The implementation of smart tourism offers the most important information sharing and transmission guarantee for the virtual tourism supply chain because the operation of the virtual supply chain is no longer based on inventory but on information. Ultimately, the booming of online travel has provided fertile ground for the full advent of the virtual tourism supply chain era. Some mature online travel companies at home and abroad (such as Expedia, Ctrip, and Taobao Travel) are deepening and exploring more comprehensive tourism products. The online platform can satisfy all needs of tourism six elements "tourism, accommodation, travel, travel, purchase, and entertainment” during the full range of tourist travel activities and other ancillary needs. The implementation of this need should rely on the full participation of a large number of offline tourism suppliers, tourism producers (tour operators), tourism vendors and other tourism service providers. The rapid growth and expansion of innovative tourism products (creative tourism, etc.) has spawned a large number of tourists customized service demands. Online travel companies will expand tourism suppliers globally in order to meet a variety of customized services, thereby breaking the traditional supply chain integration philosophy. Hence, virtual supply chain can achieve the exceeding of geographical space limitations (Fig. 3). 


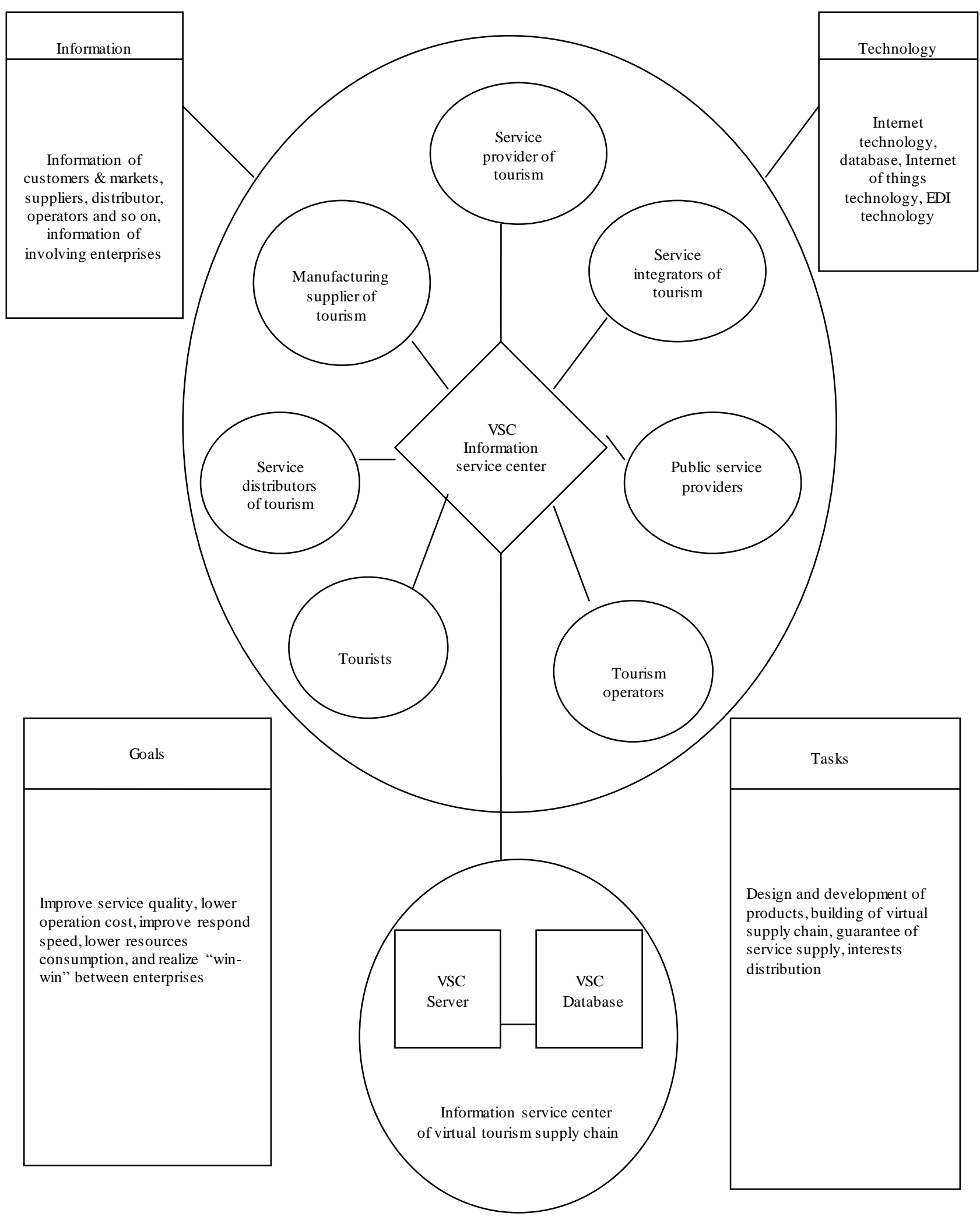

Fig. 3. System and structure of virtual tourism supply chain 


\section{Low-carbon tourism supply chain}

The green supply chain is a modern management model that realizes the sustainable development of the entire industrial group by comprehensive consideration of environmental impact and resource utilization efficiency. The integration and upgrading of the tourism industry must step into the development track of the implementation of the green tourism supply chain. At the specific implementation level, the proposal of low-carbon supply chain forms a clearer target for the green supply chain by direct reduction of carbon emissions. The low-carbon supply chain requires low production, circulation, consumption, and energy use from the supply chain level. Carbonization, compared with traditional low-carbon tourism, covers a wider scope and richer content. Low-carbon tourism emphasizes more on the low-carbon consumption and tourists' behavior, while the low-carbon supply chain rises to the entire tourism industry. The low-carbon supply chain not only requires tourists' low-carbon travel, but also emphasizes the low-carbon operation of tourism participating companies. Therefore, the research\& development and application of lowcarbon technology are particularly critical. The government's policy support and supervision is the important guarantee in the implementation of the low-carbon supply chain. The lowcarbon tourism supply chain includes, in terms of process, lowcarbonization of tourism product's development and design, low carbonization of production and manufacturing of tourism products, low-carbonization of tourism resources' supply and distribution (low-carbon logistics), low-carbon logistics of tourism travel operations, and low-carbon sales and procurement of tourism products.

\section{CONCLUSION}

Although the idea of supply chain management has gradually matured in the current Chinese business community, the tourism supply chain in the current tourism industry only stays at the initial stage of theoretical discussions. The specific practice level faces many unsolved problems and doubts, and future efforts should be focused on the following aspects: (1) the framework and network structure of the green tourism supply chain needs to be further studied. Although the paper builds a green tourism supply chain from major aspects, the structure of tourism supply chain is complex. Different functional network structures produce different supply chain operational effects. In the future, they need to be studied in deeper aspects. (2) For the tourism industry, there are prominent problems of small scale, scattered operations, low threshold, and disorderly management. In order to truly build a highly efficient and convenient modern supply chain management system in the tourism industry, the key is how to achieve mutual trust strategic partnership between tourism companies. The author analyzes from the distribution mechanism and supply contract constraints, but there are still defects and deficiencies; (3) the new forms of the tourism industry integration will inevitably give birth to a new type of tourism supply chain. The forms and structures of tourism supply chain require enriching combining new types of tourism, such as agricultural tourism, red tourism, and sports tourism.

\section{REFERENCES}

[1] Tapper RTapper R, Font X. Touris m Supply Chains[R].Report of a Desk Research Project for the Travel Foundation. Leeds Metropolitan University. Environment Business \& Development Group, 2004.

[2] Page Tourism Management : Managing for Change[M].Elsevier, Amsterdam, 2003.

[3] Zhang X, Song H. Tourism Supply Chain Management: A New Research Agenda [J].Tourism Management, 2009,(3)

[4] Wang Qijing. On the Construction of China's Tourist Industry Chain in the Transition period[J]. Journal of Jiang xi University of Finance and Economics, 2005,27,(5):63-65.

[5] Li Wanli, Yan Haopeng, Li Ping.Several Problems Regarding the Study of Tourism Supply Chain[J] ,2007,(9)

[6] Li Wanli, Li Ping. Introduction to European Tour Operators and Their Experiences of Tourism Supply Chain Management. Tourism Tribune[J]. Journal of Guilin Institute of Tourism,2006,(1) 